\title{
Novel complex $t(V ; 9 ; 22)$ rearrangements in three cases with chronic myeloid leukemia and a rare translocation in a case with classical Philadelphia chromosome
}

\author{
HASMIK MKRTCHYAN ${ }^{1,2}$, SEDA GHAZARYAN ${ }^{3}$, GAYANE AVETISYAN $^{3}$, ANNA HOVHANNISYAN ${ }^{2}$, \\ LAURA MURADYAN ${ }^{3}$, SMBAT DAGHBASHYAN $^{3}$, CONSTANZE KARST $^{1}$, MADELEINE GROSS ${ }^{1}$, \\ SOPHIE HINREINER ${ }^{1}$, ROUBEN AROUTIOUNIAN ${ }^{2}$ and THOMAS LIEHR ${ }^{1}$ \\ ${ }^{1}$ Institute of Human Genetics and Anthropology, Kollegiengasse 10, D-07743 Jena, \\ Germany; ${ }^{2}$ Yerevan State University, Alex Manoogian $1 ;{ }^{3}$ Centre of \\ Hematology and Blood Transfusion, H. Nersisyan 7,0025, Yerevan, Armenia
}

Received January 9, 2008; Accepted April 4, 2008

\begin{abstract}
The fusion gene $\mathrm{BCR} / \mathrm{ABL}$ arises in connection with a complex translocation event in $2-10 \%$ of cases with chronic myeloid leukemia (CML). Due to causative treatment with Imatinib most cases with variant rearrangements show no specific prognostic significance, though the events of therapy resistance remain to be studied. Herein we report on three CML cases with complex chromosomal aberrations not observed before, involving chromosomal regions such as $1 \mathrm{p} 32,2 \mathrm{q} 11$ and $6 \mathrm{q} 12$. Additionally we report on one case with the rare translocation $\mathrm{t}(3 ; 8)(\mathrm{p} 22 ; \mathrm{q} 22)$ along with the classic Philadelphia $(\mathrm{Ph})$ chromosome. In two cases, two different breakpoints on chromosome 22 were found. Moreover, in one of them two breakpoints on chromosome 9 were observed. The following chromosomal studies, during therapy by Imatinib, have revealed different cytogenetic responses.
\end{abstract}

\section{Introduction}

Chronic myeloid leukemia (CML) is a clonal myeloproliferative disease which arises following the $\mathrm{BCR}$ and $\mathrm{ABL}$ somatic gene rearrangement in a pluripotent bone-marrow stem cell. In 90-95\% cases with CML, the BCR/ABL fusion gene is the result of reciprocal translocation between chromosomes 9 and 22 and is cytogenetically observable as a small derivative chromosome 22 which is known as Philadelphia (Ph) chromosome (1).

In a Ph-positive CML expression of the $\mathrm{BCR} / \mathrm{ABL}$ chimeric protein p210 with an increased tyrosine kinase activity is essential for multiple signaling pathways to confer the leukemia

Correspondence to: Dr Hasmik Mkrtchyan, Institut für Humangenetik, Postfach, D-07740 Jena, Germany

E-mail: hasmik.mkrtchyan@mti.uni-jena.de

Key words: chronic myeloid leukemia, Philadelphia chromosome phenotype (2). Imatinib mesylate (Glivec, formerly STI571) was designed specifically to inhibit the tyrosine kinase activity of the bcr/abl protein and other tyrosine kinases such as c-abl, c-kit and platelet-derived growth factor receptor. By binding to an active site of the tyrosine kinase, Glivec switches off downstream signaling, cells stop proliferating and apoptosis ensues (3). Many studies have shown a high efficiency of Imatinib therapy to achieve a complete or major cytogenetic response (MCR), i.e. $0-34 \% \mathrm{Ph}$-positive cells. This positive effect may be achieved in cases with simple $t(9 ; 22)$, and complex translocations resulting in a $\mathrm{BCR} / \mathrm{ABL}$ fusion gene, as well as in cases with cytogenetic clonal evolution $(4,5)$.

Complex chromosomal rearrangements involving one or more additional chromosomes were described in $>600$ cases with CML (6). By conventional cytogenetic analysis, two variant subgroups have traditionally been recognized: complex, $\mathrm{t}(9 ; 22 ; \mathrm{V})$, where $\mathrm{V}$ represents a third translocation partner chromosome and simple, $\mathrm{t}(9 ; \mathrm{V})$ or $\mathrm{t}(22 ; \mathrm{V})(7)$. Only in a few cases is a chromosomal fragment from the third chromosome translocated to the der(22)t(9;22), producing a 'masked $\mathrm{Ph}$ ' (8). In most Ph-variant cases the segment 22q11-qter is moved to a third chromosome, while a part of the third chromosome is located on 9q34. Deletions on the derivative chromosome 9 were found to occur with a much higher frequency in patients with variant $\mathrm{Ph}$ translocations $(45 \%)$ than in those with classic $\mathrm{Ph}(17 \%)$ (9).

Herein we report on three CML cases with new complex aberrations with three or more chromosomal breakpoints which include $1 \mathrm{p} 32,2 \mathrm{q} 11$ and $6 \mathrm{q} 12$. Additionally, a case with a classic $\mathrm{Ph}$ chromosome accompanied by a rare translocation $(3 ; 8)(\mathrm{p} 22 ; \mathrm{q} 22)$ was characterized by molecular cytogenetics.

\section{Materials and methods}

Case 1. A 28-year-old male patient presented with leukocytosis. The physical examination showed splenomegaly and hepatomegaly. Blood analysis revealed the hemoglobin concentration at $9.3 \mathrm{~g} / \mathrm{l}$, the white blood count (WBC) at $204 \times 10 \%$, with blasts of $3 \%$ and thrombocytosis. 


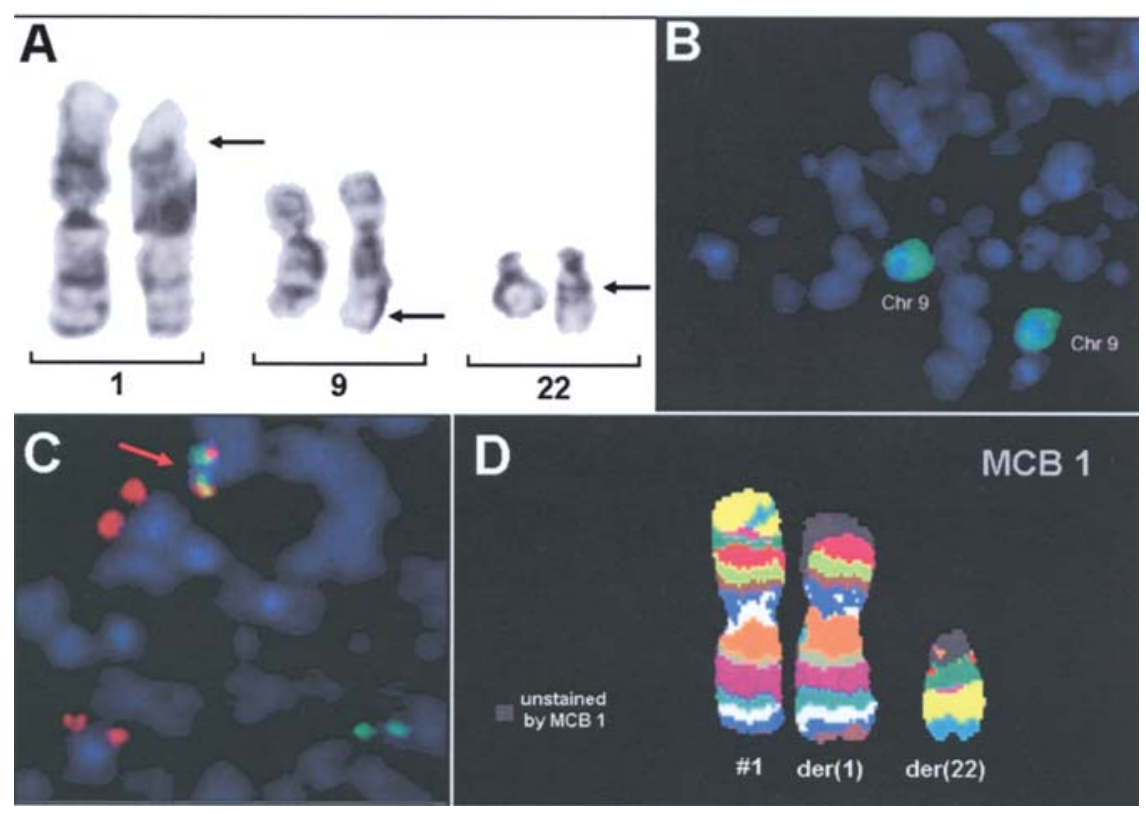

Figure 1. Case 1: (A) Partial GTG-karyogram for the aberrant chromosomes 1, 9 and 22 (arrows). (B) Whole chromosome paint (WCP) of chromosome 9 , which is apparently normal is shown. (C) Fusion gene BCR/ABL (ES LSI BCR/ABL) located on der(22). (D) Application of multicolor banding for chromosome $1(\mathrm{MCB})$ revealed a translocation of 1p32.2->1pter on the der(22).

Case 2. A 31-year-old male patient was referred to the hospital due to leukocytosis found upon routine laboratory analysis. A physical examination showed splenomegaly and hepatomegaly. The hemoglobin concentration was $140 \mathrm{~g} / \mathrm{l}$; WBC, 226x109/1 and $4 \%$ blasts and thrombocytosis were identified.

Case 3. A 20-year-old male patient was hospitalized because of leukocytosis. The physical examination revealed splenomegaly. Blood analysis showed the hemoglobin concentration at $143 \mathrm{~g} / 1$, the WBC at $70 \times 10 \% / 1$ and $2 \%$ blasts.

Case 4. A 9-year-old girl was referred to the hospital. At the physical examination splenomegaly was identified. A blood examination showed the hemoglobin concentration at $103 \mathrm{~g} / \mathrm{l}$, WBC at $373 \times 10^{9} / 1$, with $4 \%$ blasts and thrombocytosis .

Banding cytogenetics. Chromosomes were obtained from unstimulated bone marrow, cultivated for $24 \mathrm{~h}$ and treated with colcemid for $12 \mathrm{~h}$. Karyotypes were described according to the International System for Human Cytogenetic Nomenclature (10).

Fluorescence in situ hybridization. Fluorescence in situ hybridization (FISH) was performed according to standard protocols (11). In order to detect the presence of BCR/ABL fusion gene, the LSI BCR/ABL ES (Vysis) and M-BCR/ABL probes (Oncor) were used. To describe the complex karyotype, multiplex-FISH (M-FISH) and single whole chromosome painting (WCP) probes were applied. Breakpoint characterization was performed by multicolor banding (MCB). Specific BAC clones (RP11-808D16 in 1p31, RP11-45F22 in 1p32, RP11-775G6 in 22q11.2, RP11-259P1 in 22q11.2 12, RP11$387 \mathrm{~L} 5$ in $6 \mathrm{q} 12$ and RP11-708D7 in 2q12) were obtained from RPCI (http://www.chori.org/bacpac) and the Sanger
Centre (http://www.sanger.ac.uk/). Plasmid DNA was extracted by using a miniprep kit (Qiagen, Germany) and labeled by nick translation (Roche, Germany).

\section{Results}

Case 1. The presence of abnormal chromosomes 1 and 22, and a possible aberration on chromosome 9 was revealed by GTG-analysis (Fig. 1A). By applying WCP for chromosomes 1,9 and 22 a rearrangement between chromosome 1 and 22 was obvious, while chromosome 9 was apparently normal (Fig. 1B). Using an LSI BCR/ABL ES probe the CML-typical fusion gene was found on the derivative chromosome 22 and was present in $100 \%$ of the nuclei (Fig. 1D). Breakpoints of the chromosomes involved in the rearrangements were verified by MCB (Fig. 1C) and BAC clones (RP11-808D16, RP1145F22, RP11-775G6 and RP11-259P1). Thus, three derivative chromosomes were described (Table I). After a course of hydroxyurea the patient received $400 \mathrm{mg} / \mathrm{m}^{2}$ Imatinib, daily. MCR was achieved within one year of Imatinib therapy (25\% $\mathrm{Ph}^{+}$cells) (Fig. 5).

Case 2. The first three cytogenetic analyses failed and only interphase FISH using LSI BCR/ABL ES was performed. In the initial sample, $75 \%$ of the nuclei exhibited a BCR/ABL fusion gene. This rate remained the same during treatment with Imatinib (60-70\% of BCR/ABL positive cells, Fig. 5). The fourth FISH analysis detected the BCR/ABL fusion gene in $100 \%$ nuclei and GTG-banding revealed a complex $\mathrm{Ph}$ rearrangement involving chromosome 6 (Fig. 2A). The BCR/ ABL gene was identified on der(22) (Fig. 2B). FISH analysis using MCB and BAC clones RP11-387L5 for 6q12 precisely characterized the chromosomal aberration as a $\mathrm{t}(6 ; 9 ; 22)$ (q12;q34;q11) (Fig. 2C-E). In addition to this presumably 
Table I. Molecular cytogenetic results of patients with CML with complex aberrations.

\begin{tabular}{|c|c|c|c|}
\hline Case & Gender/age & GTG-banding results & Multicolor FISH results \\
\hline 1 & $\mathrm{M} / 28$ & $46, \mathrm{XY}, \mathrm{t}(1 ; 22)$ & $\begin{array}{l}46, X Y, \\
\operatorname{der}(1)(22 q t e r->22 q 12.1:: 1 \mathrm{p} 32.2->1 \mathrm{qter}), \\
\operatorname{der}(9)(9 \text { pter->9q34.1::22q11.2->22q12.1::9q34.3->9qter), } \\
\operatorname{der}(22)(22 p t e r->22 q 11.2:: 9 \mathrm{q} 34.1->9 \mathrm{q} 34.3:: 1 \mathrm{p} 32.2->1 \mathrm{pter})\end{array}$ \\
\hline 2 & $\mathrm{M} / 31$ & $\begin{array}{l}46 \sim 47, X Y, t(6 ; 9 ; 22) \\
+8, i(17 q)\end{array}$ & $46 \sim 47, X Y, t(6 ; 9 ; 22)(q 12 ; q 34 ; q 11),+8, i(17)(q 10)$ \\
\hline 3 & $\mathrm{M} / 20$ & $\begin{array}{l}46, X Y,-2,-22, \\
+\operatorname{mar} 1,+\operatorname{mar} 2\end{array}$ & $\begin{array}{l}46, X Y, t(2 ; 22)(\mathrm{q} 11.2 ; \mathrm{q} 11.1)[17] / \\
46, \mathrm{XY}, \operatorname{der}(2) \mathrm{t}(2 ; 22)(\mathrm{q} 11 ; \mathrm{q} 11.1) \mathrm{t}(22 ; 9)(\mathrm{q} 11.2 ; \mathrm{q} 34), \\
\operatorname{der}(9) \mathrm{t}(9 ; 22)(\mathrm{q} 34 ; \mathrm{q} 11.2), \operatorname{der}(22) \mathrm{t}(22 ; 2)(\mathrm{q} 11.1 ; \mathrm{q} 11)[16]\end{array}$ \\
\hline 4 & $\mathrm{~F} / 9$ & $\begin{array}{l}46, X X, \mathrm{del} / \mathrm{t}(3 \mathrm{p} 2 ?), \\
\mathrm{t}(9 ; 22)(\mathrm{q} 34 ; \mathrm{q} 11)\end{array}$ & $46, \mathrm{XX}, \mathrm{t}(3 ; 8)(\mathrm{p} 22 ; \mathrm{q} 22), \mathrm{t}(9 ; 22)(\mathrm{q} 34 ; \mathrm{q} 11)$ \\
\hline
\end{tabular}
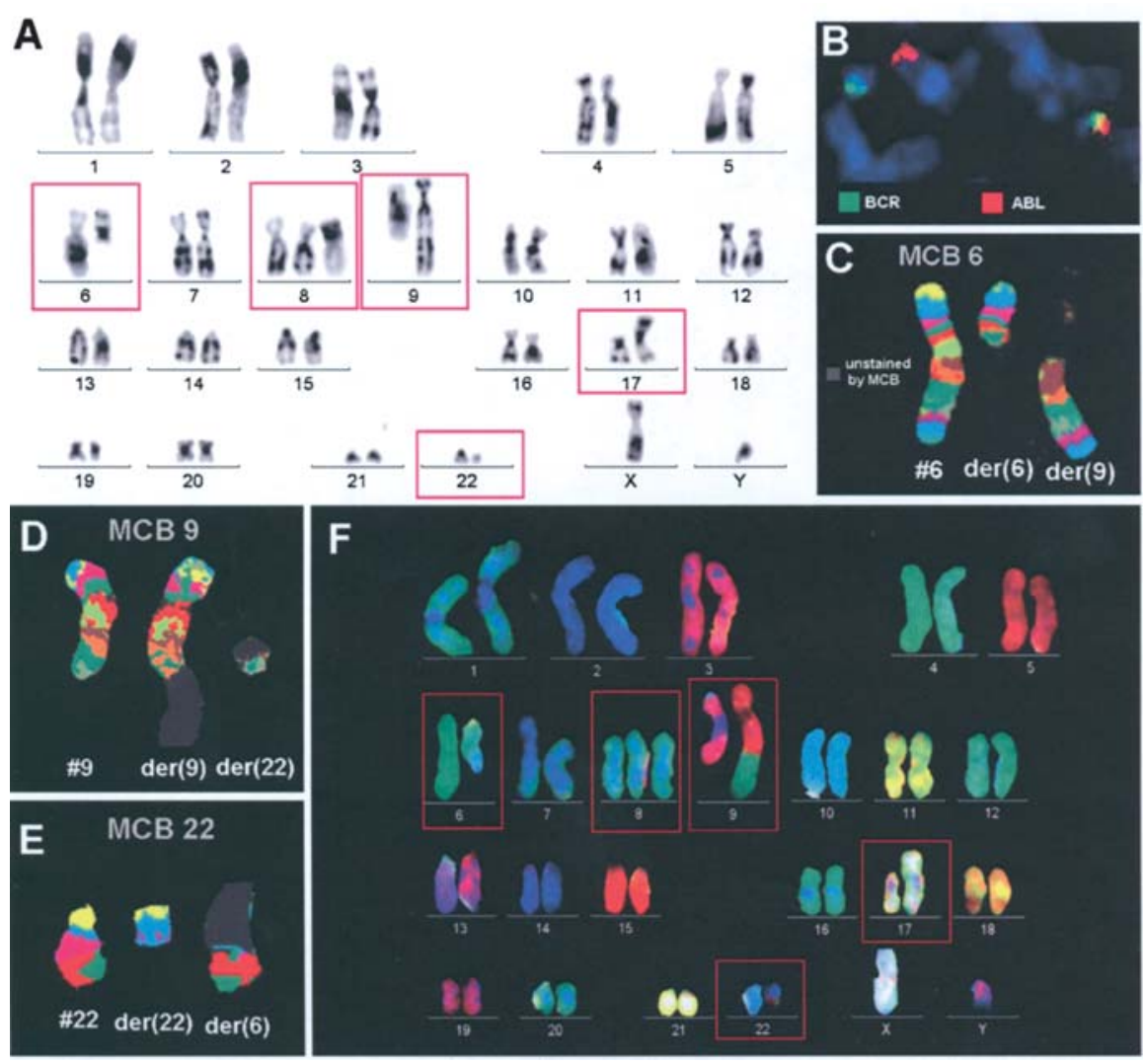

Figure 2. Case 2: (A) Karyotype: 47,XY,t(6;9;22) (q12; $34 ; ; \mathrm{q} 11),+8, \mathrm{i}(17)(\mathrm{q} 10)$ (aberrant chromosomes highlighted by frames). (B) The gene-fusion $\mathrm{BCR} / \mathrm{ABL}$ is located on der(22). (C-E) The application of MCB 6 (C), 9 (D) and 22 (E) has revealed the chromosomal breakpoints. (F) M-FISH confirmed the complexity of the karyotype.

primary complex translocation event, secondary chromosomal aberrations were found. By using M-FISH, a trisomy 8 and an isochromosome 17q10 were verified (Fig. 2F). After a course of hydroxyurea the patient received $400 \mathrm{mg} / \mathrm{m}^{2}$ Imatinib, but has shown resistance to the treatment (short hematological and minor cytogenetic response $\left(60 \% \mathrm{Ph}^{+}\right.$cells within 19 months). The bone marrow was studied briefly 4 times: the first at initial diagnosis, and again after 13, 19 and 28 months (Fig. 5). The patient succumbed 30 months after diagnosis.
Case 3. A primary interphase FISH analysis showed the presence of a BCR/ABL fusion gene in $100 \%$ of the nuclei. The chromosome quality was not sufficient for GTG-banding. After chemotherapy with hydroxyurea, followed by Imatinib, a secondary cytogenetic study was performed. The BCR/ABL fusion gene was proven in only $44 \%$ of the cells. Using GTGbanding two aberrant chromosomes were identified whose origin was discovered by the WCP probes of chromosomes 2 and 22 (Fig. 3A). Two cell clones with different variants of 


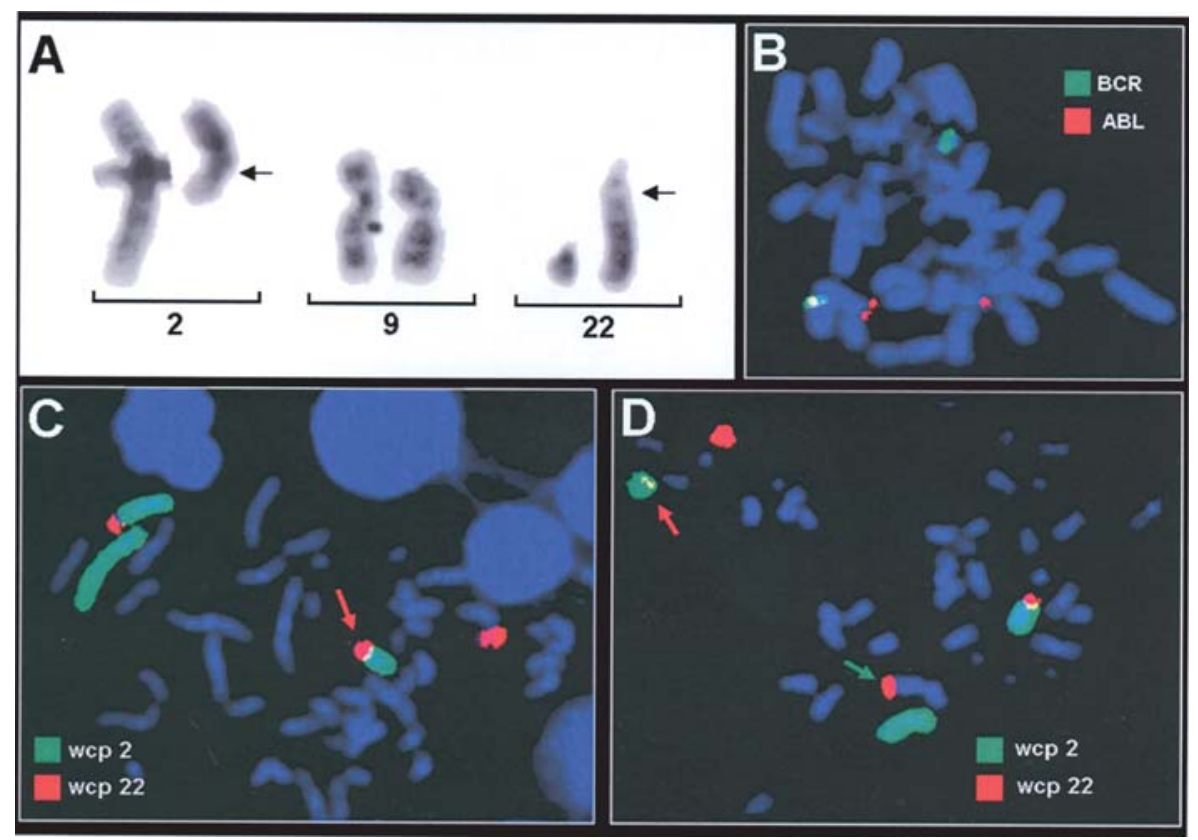

Figure 3. Case 3: (A) Aberrant chromosomes 2 and 22 are shown, while chromosome 9 is apparently normal (arrows). (B) The fusion gene BCR/ABL (ES LSI $\mathrm{BCR} / \mathrm{ABL}$ ) is located on der(2). (C-D) Using WCP for chromosomes 2 (green) and 22 (red) two cell clones were found. In one clone the fragment of chromosome 22q11.1->22qter is located on chromosome 2 (red arrow), while chromosome 9 is not included in the rearrangement (C). In the second clone the chromosomal region 22q11.1->q11.2 is transferred on the derivative chromosome 2 (red arrow), as the fragment 22q11.2->22qter is on der(9) (green arrow in D).

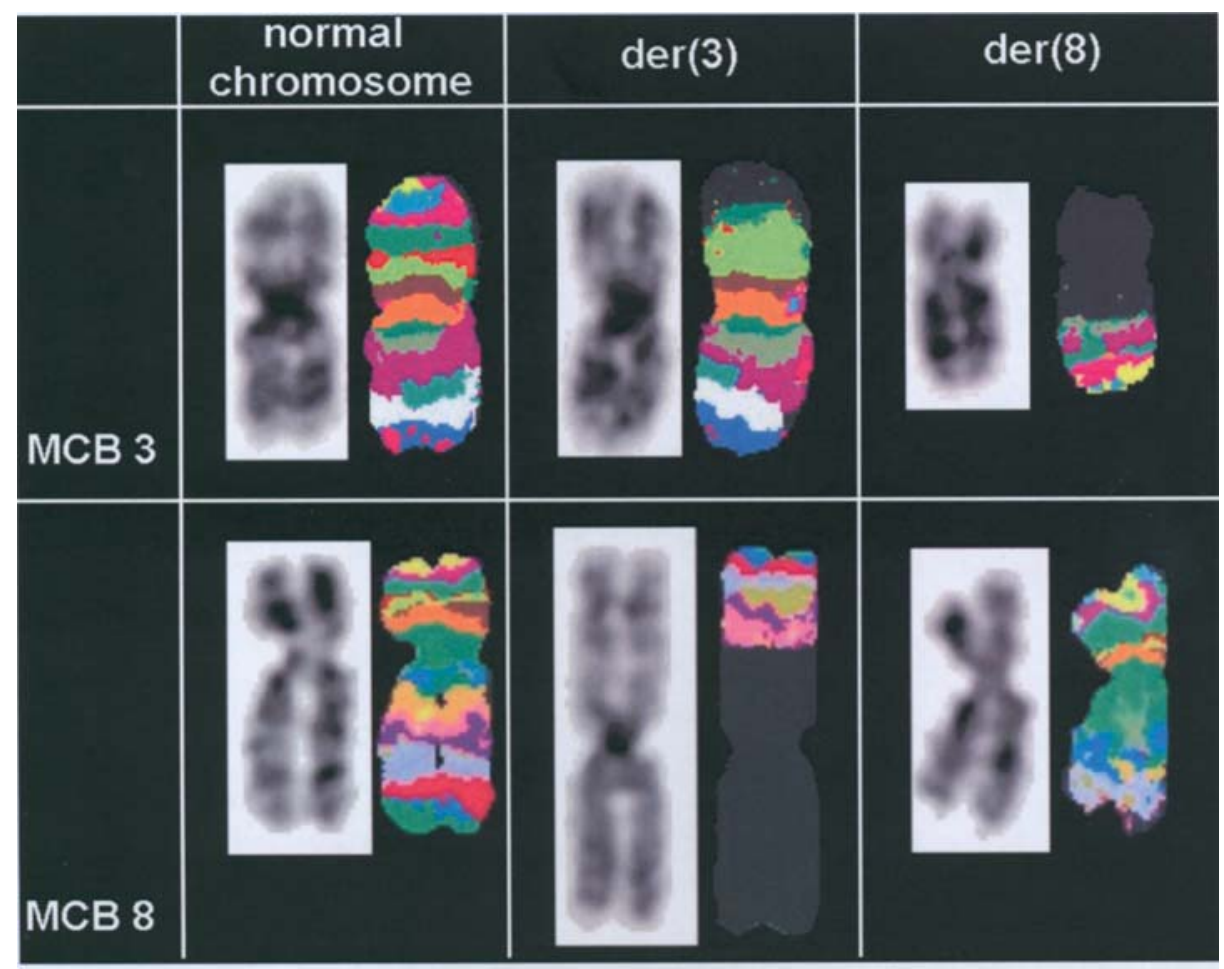

Figure 4. MCB of chromosomes 3 and 8 in case 4.

the rearrangement were characterized. In the first clone 22q11.1->qter was located on chromosome 2, while chromosome 9 was not included in the rearrangement (Fig. 3C). In the second clone, on chromosome 22 two breaks occurred as a result of which the chromosomal region $22 \mathrm{q} 11.1->\mathrm{q} 11.2$ was translocated on the derivative chromosome 2 and the fragment 22q11.2->qter was detectable on der(9) (Fig. 3D). The application of LSI BCR/ABL has shown the CML-typical fusion gene on the der(2) in the second clone (Fig. 3B). After a course of hydroxyurea the patient received $400 \mathrm{mg} / \mathrm{m}^{2}$ Imatinib, daily. The follow-up cytogenetic studies have shown a decrease in the number of nuclei with BCR/ABL (Fig. 5). 


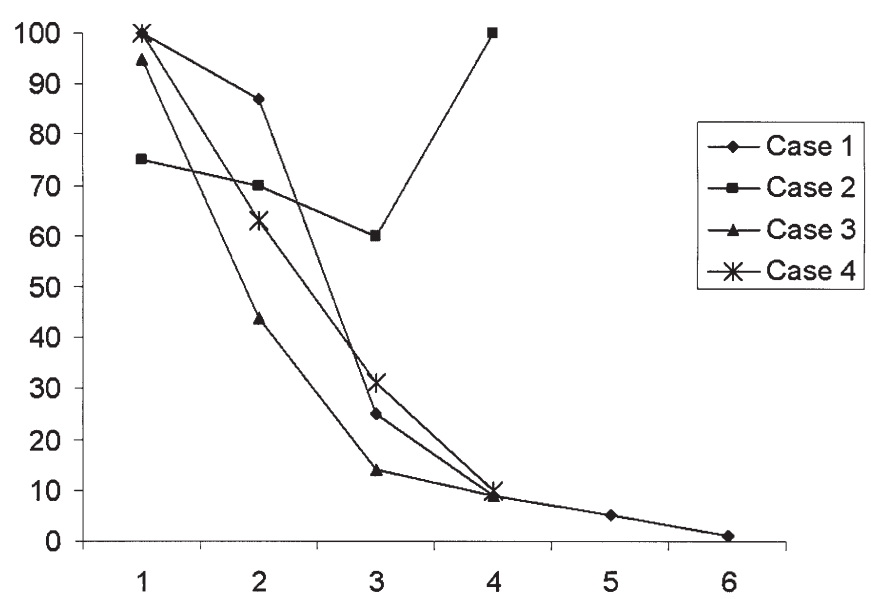

Figure 5. The monitoring of the presence of fusion gene BCR/ABL in Imatinib therapy patients with CML occurred as reported herein by interphase FISH using an ES LSI BCR/ABL probe. In case 1, the repeated analyses were performed 6 times, in case 2 three times, in cases 3 and 4 four times each.

Case 4. In this case GTG-banding revealed a classical $\mathrm{Ph}$ chromosome and a deletion or translocation of the short arm of chromosome 3. The BCR/ABL fusion gene was found in $100 \%$ of the nuclei and metaphases. Using the WCP probes of chromosomes 3 and 8 we verified a translocation. The chromosomal break-points were characterized by MCB probes (Fig. 4A and B). After a course of hydroxyurea the patient received $400 \mathrm{mg} / \mathrm{m}^{2}$ Imatinib, daily. MCR was achieved within one year $\left(31 \% \mathrm{Ph}^{+}\right.$cells) and the follow-up study showed only $10 \% \mathrm{Ph}^{+}$cells after 6 months (Fig. 5).

\section{Discussion}

According to the literature, in 2-10\% CML cases the fusion gene BCR/ABL is a result of a complex translocation. At present it appears that variant translocations can affect any chromosome. However, it has been suggested that distribution of the break-points is non-random with the chromosomal bands most susceptible to breakage being: 1p36, 3p21, 5q31, $6 \mathrm{p} 21,9 \mathrm{q} 22,10 \mathrm{q} 22,11 \mathrm{q} 13,12 \mathrm{p} 13,17 \mathrm{p} 13,17 \mathrm{q} 21,17 \mathrm{q} 25$, $19 \mathrm{q} 13,21 \mathrm{q} 22,22 \mathrm{q} 12$ and $22 \mathrm{q} 13$ (6).

In our study we revealed three cases with CML with complex translocations, involving different chromosomes. These cases were BCR/ABL positive. In one case the BCR/ $\mathrm{ABL}$ fusion gene was located on the derivative chromosome 2, while in others localization was on $\operatorname{der}(22)$. As breakpoints of the third chromosome we identified 1p32, 2q11 and $6 \mathrm{q} 12$. The breakpoint $6 \mathrm{q} 12$ was not previously described in CML but 1 p32 and 2 q11 have been mentioned in the catalogue of chromosome aberrations in cancer 2 and 3 times, respectively, in CML (12).

Two possible mechanisms for variant translocation formation were suggested. The first is a single-event rearrangement via the simultaneous breakage of several chromosomes followed by mismatched joining (13). Nacheva et al proposed a classical $\mathrm{Ph}$ translocation followed by a further translocation event between chromosomes 9 and 22 plus a third chromosome (14). The mechanism of the formation of a variant Ph trans- location may have prognostic importance in that a two-event mechanism represents clonal evolution, whereas a variant translocation occurring via a single genomic rearrangement may confer a similar prognosis to the classical $\mathrm{Ph}$ translocation (15).

Two of our cases have demonstrated a two-way mechanism of the formation of the variant translocation. During the first cytogenetic diagnosis in case 3 with a $\mathrm{t}(2 ; 22 ; 9 ; 22), \mathrm{BCR} / \mathrm{ABL}$ fusion gene was observed in $100 \%$ nuclei by interphase FISH, while the second cytogenetic investigation after the course of Imatinib therapy revealed the presence of two clones: i) a $\mathrm{Ph}-$ chromosome negative clone with $\mathrm{t}(2 ; 22)(\mathrm{q} 11.2$ ?;q11) and ii) with a complex translocation with the BCR/ABL gene on der(2). Notably, t(2;22) was apparently a primary chromosomal change, and probably, BCR/ABL was a result of the translocation between $\operatorname{der}(2) \mathrm{t}(2 ; 22)$ and chromosome 9 . To the best of our knowledge the chromosomal breakpoint 2q11 has already been described in complex aberrations with 9 and 22 . However, two breakpoint events on chromosome 22 were not found previously in the formation of $\mathrm{t}(2 ; 9 ; 22)(16-18)$.

In case 1 the translocation $(9 ; 22)$ appears to be the first chromosomal event. Further rearrangement developed with a new breakpoint on the der(9), der(22) and on chromosome 1. Cytogenetic studies after Imatinib therapy revealed cells without any chromosomal aberrations. The chromosomal region $1 \mathrm{p} 32.2$ has yet to be described as a partner in a complex translocation in CML.

The variant $\mathrm{Ph}$ translocation involving chromosome 6 was described in case 2 . As the complex aberration was detected in the later phase of the disease, the significance of the rearrangement could not be determined. The patient has also shown complex karyotype with trisomy 8 and isochromosome 17q. Additional chromosomal aberrations are thought to result in a higher genome instability of tumor cells. Trisomy 8 is one of the most frequent aneuploidies in CML patients. According to the literature +8 has no prognostic significance in CML patients (19). Isochromosome (17)(q10) is one of the non-random changes occurring in CML progression. This aberration is associated with the loss of the tumor suppressor gene TP53 and mostly with poor prognosis (6). In addition, the monitoring of responses to Imatinib has revealed that CML cases with $\mathrm{i}(17 \mathrm{q})$ had lower rates of complete or major cytogenetic responses. Notably, the presence of trisomy 8 was associated with a relatively high cytogenetic response rate (5). To explain the cytogenetic resistance to Imatinib $\mathrm{Ph}^{+}$ cases with CML with secondary genetic abnormalities Mohamed et al suggested that the $\mathrm{Ph}^{+}$leukemic cells no longer depend on BCR/ABL for survival (20).

In case 4 we found a translocation of chromosomes 3 and 8 along the classical $\mathrm{Ph}$. Only CML-associated features were detected in the patient. Breakages of the long arm of chromosome 3 during the clonal evolution of CML were well described in previous literature while the region $3 \mathrm{p} 22$ has been known to be a partner of chromosomal rearrangements mostly in solid tumors (12). Killary et al defined a tumor suppressor locus within the human chromosome 3p21-22 using a rapid functional assay system (21). The aberrations including the second chromosomal region $8 \mathrm{q} 22$ have been found in different neoplastic malignancies as well as in acute myeloid leukemia M2 (22) and the myelodysplastic syndrome 
(23). After the therapy course in Ph-negative cells this aberration was still present. Due to different circumstances the investigation of other tissues has not been performed to define the origin of the translocation. The observation made by Hild and Fonatsch suggested that chromosomal abnormalities observed in addition to the $\mathrm{Ph}$ chromosome at the time of the initial diagnosis may not be associated with poor prognosis (24). A constitutional aberration could also not be ruled out in these cases.

The monitoring of BCR/ABL by interphase FISH during Imatinib treatment has shown a major cytogenetic response in three cases, except that of $t(6 ; 9 ; 22)$. In this study it was not possible to make a significant prognosis of the complex cytogenetic events. However, based on our results, we conclude that patients with variant $\mathrm{Ph}$ translocations and a translocation $(3 ; 8)$ without clonal evolution respond well to Imatinib therapy. In summary, our study demonstrates that applying the LSI-probes, M-FISH and MCB allow to comprehensively characterize complex chromosomal rearrangements that were not identified by banding cytogenetics alone.

\section{Acknowledgements}

Supported in part by the Ernst-Abbe-Stiftung, the INTAS (AISbl 03-51-4060), the Deutsche Krebshilfe/Mildred Scheel Stiftung für Krebsforschung (70-3125-Li1), the IZKF Jena (Start-up S16), the DFG ((LI 820/9-1, 436 ARM 17/2/04 and 436 ARM 17/5/06), the UICC (ICR/05/030), the Stiftung Leukämie and the IZKF together with the TMWFK (TP 3.7 and B307-04004).

\section{References}

1. Rooney DE: Human Cytogenetics Malignancy and Acquired Abnormalities. 3rd edition, Oxford University Press, New York, p37, 2001.

2. Lugo T, Pendergast A, Müller A and Witte O: Tyrosine kinase activity and transformation potency of bcr-abl oncogene products. Science 247: 1079-1082, 1990.

3. Griffen J: The biology of signal transduction inhibition: basic science to novel therapies. Semin Oncol 28: 3-8, 2001.

4. Kantarjian H, Sawyers C, Hochhaus A, et al: Hematologic and cytogenetic responses to imatinib mesylate in chronic myelogenous leukemia. N Engl J Med 346: 645-652, 2002.

5. Cortes JE, Talpaz M, Giles F, O'Brien S, Rios MB, Shan J, Garcia-Manero G, Faderl S, Thomas DA, Wierda W, Ferrajoli A, Jeha $S$ and Kantarjian HM: Prognostic significance of cytogenetic clonal evolution in patients with chronic myelogenous leukemia on imatinib mesylate therapy. Blood 101: 3794-3800, 2003.

6. Johansson B, Fioretos T and Mitelman F: Cytogenetic and molecular genetic evolution of chronic myeloid leukemia. Acta Haematol 107: 76-94, 2002.

7. Huret JL: Complex translocations, simple variant translocations and $\mathrm{Ph}$-negative cases in chronic myelogenous leukaemia. Hum Genet 85: 565-568, 1990.
8. Hagemeijer A, de Klein A, Godde-Salz E, Turc-Carel C, Smit EME, van Aghtoven AJ and Grosveld GC: Translocation of c-abl to 'masked' $\mathrm{Ph}$ in chronic myeloid leukemia. Cancer Genet Cytogenet 18: 95-104, 1985.

9. Reid A, Gribble SM, Huntly BJ, Andrews KM, Campbell L, Grace CD, Wood ME, Green AR and Nacheva EP: Variant Philadelphia translocations in chronic myeloid leukaemia can mimic typical blast crisis chromosome abnormalities or classic $\mathrm{t}(9 ; 22)$ : a report of two cases. Br J Haematol 113: 439-442, 2001.

10. ISCN An International System for Human Cytogenetic Nomenclature. Mitelman F (ed). Karger, Basel, 1995.

11. Rautenstrauss B and Liehr T: FISH Technology. Lab Manual. Springer-Verlag, Berlin, pp77-81, 2002.

12. Mitelman F, Johansson B, Mertens F and Mitelman F: Database of chromosome aberrations in cancer: http://cgap.nci.nih.gov/ Chromosomes/RecurrentAberrations, 2007.

13. Fitzgerald PH and Morris CM: Complex chromosomal translocations in the Philadelphia chromosome leukemias. Serial translocations or a concerted genomic rearrangement? Cancer Genet Cytogenet 57: 143-151, 1991.

14. Nacheva E, Holloway T, Brown K, Bloxham D and Green AR: Philadelphia-negative chronic myeloid leukaemia: detection by FISH of BCR-ABL fusion gene localized either to chromosome 9 or chromosome 22. Br J Haematol 87: 409-412, 1994.

15. Reid AG, Huntly BJP, Grace C, Green AR and Nacheva EP: Survival implications of molecular heterogeneity in variant Philadelphia-positive chronic myeloid leukaemia. Br J Haematol 121: 419-427, 2003

16. Alimena G, Dallapiccola B, Gastaldi R, Mandelli F, Brandt L, Mitelman F and Nilsson PG: Chromosomal, morphological and clinical correlations in blastic crisis of chronic myeloid leukaemia: a study of 69 cases. Scand J Haematol 28: 103-117, 1982.

17. Smadja N, James J, Krulik M, Zittoun R and Debray J: Chronic myelogenous leukemia with a Philadelphia chromosome resulting from a complex translocation $(2 ; 9 ; 22)$, following an undifferentiated acute leukemia. Cancer Genet Cytogenet 8: 1-8, 1983.

18. Gorusu M, Benn P, Li Z and Fang M: On the genesis and prognosis of variant translocations in chronic myeloid leukemia. Cancer Genet Cytogenet 173: 97-106, 2007.

19. Heim S and Mitelman F: Cancer Cytogenetics: Chromosomal and Molecular Genetic Aberrations of Tumor Cells. 2nd edition, Willey-Liss, New-York, p57, 1995.

20. Mohamed AN, Pemberton P, Zonder J and Schiffer CA: The effect of Imatinib mesylate on patients with Philadelphia chromosome-positive chronic myeloid leukemia with secondary chromosomal aberrations. Clin Cancer Res 9: 1333-1337, 2003.

21. Killary AM, Wolf ME, Giambernardi TA and Naylor SL: Definition of a tumor suppressor locus within human chromosome 3p21-p22. Proc Natl Acad Sci USA 89: 10877-10881, 1992.

22. Pedersen-Bjergaard J and Rowley JD: The balanced and the unbalanced chromosome aberrations of acute myeloid leukemia may develop in different ways and may contribute differently to malignant transformation. Blood 83: 2780-2786, 1994.

23. Odero MD, Grand FH, Iqbal S, Ross F, Roman JP, Vizmanos JL, Andrieux J, Lai JL, Calasanz MJ and Cross NC: Disruption and aberrant expression of HMGA2 as a consequence of diverse chromosomal translocations in myeloid malignancies. Leukemia 19: $245-252,2005$.

24. Hild F and Fonatsch C: Cytogenetic peculiarities in chronic myelogenous leukemia. Cancer Genet Cytogenet 47: 197-217, 1990 